\title{
Study on the Effect of Standardization on Energy Demand and Economic Growth
}

\author{
Ren Liu ${ }^{1}$, Zhonghang Wang ${ }^{1}$, Haihong Chen ${ }^{1}$, Jie Yang ${ }^{1}$ \\ ${ }^{1}$ China National Institution of Standardization, Beijing, 100191, China
}

\begin{abstract}
The 14th Five-Year Plan is the first five-year period in which China begins a new journey to build a modern socialist country in an all-round way, and also the first five-year period after China set a goal of achieving carbon neutrality by 2060. In this important historical context, the energy development of China during the 14th Five-Year Plan period will be of great historical transformation significance. As a crucial factor, the trend of energy development during the 14th Five-Year will have a direct impact on the medium and long-term economic and social development, as well as on our confidence in achieving the goal of carbon neutrality. The improvement of standardization is conducive to promoting China's energy demand and economic growth, and it plays an important role in peaking carbon dioxide emissions and reaching the goal of carbon neutrality in the future.
\end{abstract}

\section{Introduction}

The economic transformation led by "Ecological Civilization", "Beautiful China" and the goal of carbon neutrality has charted a new growth path for China, which can promote industrial transformation and upgrading, enhance competitiveness, increase job opportunities, advance the structural transformation of the economy, improve the health of citizens by reducing air pollution, and create a better environment. China has become a global leader in emerging green technologies (such as photovoltaic modules, batteries and electric vehicles), and is gradually developing into a leading country in $5 \mathrm{G}$ technology and artificial intelligence. Properly laid out, the new growth path will accelerate the innovation and development of these emerging industries. Investment in low-carbon technologies and talents will also speed up the innovation and development in such industries, thus driving the growth of the new green economy around the world. The new growth path will cement China's position as an international leader in science and technology in the $21^{\text {st }}$ century, help promote the healthy industrial transformation in China, and improve long-term economic competitiveness. The goal of carbon neutrality will facilitate China's industrial restructuring from a highpollution, high-carbon industry mode to a low-carbon one. The low-carbon transformation will raise the total factor productivity of industries, change the mode of production and foster new business models, so as to achieve the overall goal of structural adjustment, optimization and upgrading.

In addition, as one of the world's largest consumers of crude oil, China has surpassed the United States to become the world's largest crude oil importer in $2018^{[1]}$. China is also the world's largest consumer and importer of coal. In 2019, China's coal consumption reached 2.87 billion tons of standard coal, accounting for $53 \%$ of the total global coal consumption, and its coal imports accounted for $21 \%$ of the total global coal imports ${ }^{[2,3]}$ China's heavy dependence on imported fossil fuels has weakened its energy security. Achieving the goal of carbon neutrality, however, will help increase the installed capacity for domestic renewable energy and reduce the dependence on imported fossil fuels, thus improving the national energy security level ${ }^{[4,5]}$.

The old model of economic growth and development is coming to an end, and China is about to open a new chapter of development under the guidance of a new vision. The goal of carbon neutrality is the foundation of the new vision. It will encourage green, efficient and sustainable consumption and production, build higherquality and more open, inclusive and cohesive economic, political and social systems, and promote the ecological progress in harmony between man and nature.

\section{Review of Energy Development during the 13th Five-Year Plan Period}

\subsection{The total target has been achieved, and the intensity target has been affected by the COVID- 19 epidemic}

In the first four years of the 13th Five-Year Plan period, the growth rate of China's total energy consumption was at a relatively low level. Affected by the COVID-19 epidemic, China's economic growth rate had suffered a sharp decline to $-6.8 \%$ in the first quarter of 2020 , then recovered gradually thereafter. The growth rate of energy 
consumption also changed in the same direction, but the fluctuation was smaller than that of the overall economic growth rate. According to preliminary estimates, China's total energy consumption in 2020 was 4.97 billion tons of standard coal, with an increase of about $2 \%$, and the national total control target for the 13th Five-Year Plan had been achieved. Energy consumption per unit of GDP continued to decline in the first four years, and the decrease was slight in 2020 due to the COVID-19 epidemic. Following a plummet by $5.7 \%$ in 2015 , the rate of reduction in energy consumption per unit of GDP slowed down, falling by $13.2 \%$ cumulatively in the first four years of the 13th Five-Year Plan period. Currently, the substitution elasticity of energy and capital in China is weak, while that of labor is relatively high. In 2020, energy-intensive industries suffered relatively little from the negative impact of COVID-19. Energy use by public utilities and households was not reduced and even maintained a relatively high growth rate. Therefore, energy consumption per unit of GDP increased significantly in the first quarter, and was still going up slightly year-on-year in the first three quarters. According to preliminary estimates, energy consumption per unit of GDP fell only slightly in 2020, contributing to a cumulative drop of about $13.5 \%$ during the 13th Five-Year Plan period. Although this was 1.5 percentage points short of the pre-set target, such achievement has not come easily. The elasticity coefficient of energy consumption was slightly lower than 0.5 in general, and rebounded to 1 in 2020 due to the COVID-19 epidemic. The elasticity coefficient of energy consumption in the first four years of the 13th Five-Year Plan was 0.1 lower than that in the same period of the 12th Five-Year Plan. In 2020, the elasticity coefficient increased to about 1.0 due to COVID-19. During the 13th Five-Year Plan period, China has achieved, in general, the goal that every $1 \%$ increase in energy consumption supports economic growth of more than $2 \%$, with an energy elasticity coefficient slightly lower than 0.5. As economic growth slows down, the decline process of the elasticity coefficient of energy consumption is crucial to whether the energy consumption per unit of GDP will keep falling fast.

\subsection{Comprehensive progress has been made in energy infrastructure}

The scale of clean energy supply increased substantially, and the target for the proportion of non-fossil energy was over-fulfilled. According to preliminary estimates, in terms of primary energy production, the proportion of raw coal, crude oil, natural gas and primary power production decreased to $67.7 \%, 6.7 \%, 6.1 \%$ and $19.5 \%$ respectively. From the perspective of consumption structure, the proportion of fossil energy declined steadily from $87.9 \%$ to $83.8 \%$, among which the proportion of coal decreased to $57 \%$, that of oil basically remained stable at $18.5 \%$, and that of natural gas increased to $8.3 \%$. The proportion of non-fossil energy rose to around $16 \%$, about 1 percentage point higher than the preset goal. Energy infrastructure construction has been promoted continuously, and energy storage and transportation capacity has increased significantly. By the end of 2020, China's total installed power generation capacity had exceeded 2.1 billion KW, of which 900 million $\mathrm{KW}$, or more than $40 \%$, had been generated from non-fossil energy sources. According to the white paper Energy in China's New Era, China has built more than 87,000 kilometers of natural gas trunk pipelines, 55,000 kilometers of oil trunk pipelines, and 302,000 kilometers of transmission lines of $330 \mathrm{KV}$ and above. Nine national oil reserve projects have been completed, and a natural gas reserve system has been initially established. The capacity of energy storage, transportation and peak regulation has been greatly improved. The comprehensive energy emergency support capability has been significantly enhanced, which has stood the test in the prevention and control of COVID- 19 .

\subsection{Continued progress has been made in energy reform}

Positive progress has been made in market-oriented reform, and the business environment in energy sector has been further improved. During the 13th Five-Year Plan period, China has actively promoted market-oriented reform in energy sector to encourage competition and reduce costs. The National Petroleum and Natural Gas Pipeline Network Group has been established. Market access has been further relaxed, and the oil and gas exploration and exploitation market further liberalized. Such energy trading platforms as petroleum and gas exchange centers and coal trading centers have been established. The scale of power transmission across provinces and regions has increased greatly. In 2020, China's market-based electricity consumption reached 3 trillion $\mathrm{KWH}$, accounting for nearly $40 \%$ of the total electricity consumption. The overall energy cost of market players has dropped, and the cost of renewable power generation has been falling fast. During the 13th Five-Year Plan period, affected by fluctuations in the international supply and demand pattern, crude oil prices generally run low. With the gradual relaxation on price control of unconventional gas, the price system of valve stations for residents has been gradually straightened out. Reform of power system significantly lowered the level of electricity prices. Electricity prices for general industry and commerce fell sharply, and industrial tariff also dropped significantly, thus reducing the electricity burden on enterprises. The unit cost of photoelectricity and wind power decreased dramatically with the expansion of market size and technological progress. Driven by cooling temperatures, import restrictions and a much stronger domestic economic recovery than expected, coal prices rose sharply at the end of the 13th Five-Year Plan period.

\subsection{Conditions for energy use by residents have been improved}

Strong progress has been made in the clean heating project in northern China, with the rate of clean heating reaching over $60 \%$. Since 2017 , thanks to the strong efforts of governments at all levels, the clean heating project in northern China has achieved remarkable results, with the 
rate of clean heating exceeding $60 \%$, an increase of at least 25 percentage points over 2016, replacing about 140 million tons of bulk coal. All levels of government finance and households have also paid a high economic cost for it. The proportion of solid fuels such as coal and firewood in household cooking energy use has continued to decline. The indoor and outdoor air quality has improved significantly. Rural electricity supply has been improved, and photovoltaic poverty alleviation has served multiple purposes. After addressing comprehensively the problem of the population without electricity in 2015, China has implemented a new round of renovation and upgrading for rural power grids, with the average outage time in rural areas reduced to 15 hours, and the qualified rate of comprehensive voltage increased to $99.7 \%$. Power generation has become available to all rural areas covered by the country's large grid, with the rural electrification rate reaching $18 \%$. A photovoltaic poverty alleviation project has been implemented in accordance with local conditions, which can generate electricity revenue of about RMB 18 billion annually, and benefit more than 4 million poor households.

\section{Barriers to Energy Development}

\subsection{Energy technology standard system is in urgent need of development}

Under the background of ensuring national energy security and coping with climate change, the status of energy science and technology innovation is becoming increasingly prominent. Energy technology foresight is one of the prerequisites for optimizing policies for energy industry. A little mistake may result in great waste. However, due to the uncertainty of technological evolution and different understanding of the law of technological development, it is difficult for all stakeholders to accurately grasp the development trend of energy technology. Market players have different views on the development routes of new energy technologies such as energy storage, hydrogen energy and new energy vehicles. With the development of integrated, intelligent and networked energy systems, the promotion and application of new energy technologies will be more influenced by the business environment and regulatory system, which puts forward higher requirements for the coordination and cooperation among the functional departments of the government.

\subsection{The mechanism standards for carbon trading market still need to be improved}

Trading of energy use rights and carbon emission rights is one of the means to save energy and cope with climate change. Carbon markets have been implemented or tried out in some countries or regions for many years, but there are still many difficulties. At present, corporate carbon accounting mainly relies on accounting of the physical amount of energy consumption. Due to the large and varied number of energy-using enterprises and workshops, the complex and constantly changing energy-using technologies and processes, and the numerous energyusing information that is difficult to monitor, there is a very serious information asymmetry between the regulatory authorities, their entrusted third parties and the energy users. Physical amount accounting is more complex and more difficult to regulate than financial accounting, and there is more room for manipulation and collusion. There are huge difficulties both in setting quotas and in verifying data, and, if not done properly, it can create market distortions. The free quota is essentially a planning tool and needs to be transitioned to an auction as soon as possible. Building a trading market for energy use rights and carbon emission rights will be a long-term process that requires sustained efforts and experience.

\section{Possibilities for Future Energy Development}

At the UN General Assembly and Climate Ambition Summit 2020, President Xi Jinping announced China's goals of "peaking carbon dioxide emissions by 2030 and achieving carbon neutrality by 2060 " and "realizing a $25 \%$ share of non-fossil energy by 2030", which put forward higher requirements for China's future economic and energy development. Energy system runs through various fields such as society, economy and ecological environment. As the main front in addressing climate, environment and resource issues, it will surely shoulder a greater historical mission. During the 14th Five-Year Plan period, the theme of "clean, low carbon, safe and efficient" energy development and transformation will be more distinct, the weight of energy system transformation in the work of all levels of governments and all sectors will be increased considerably, there will be more state capital, nongovernmental capital and fiscal funds flowing into the sectors related to energy transformation, and intelligent energy industry will become an important source of economic growth and will support the transformation of energy system.

\subsection{Growth in energy demand is slowing down}

The changing international situation and global COVID19 have added uncertainty to China's future development. If the world can get out of the COVID-19 dilemma early, the recovery of China's foreign trade will be expected to accelerate, and the domestic and international dual circulations will be driven in the same direction. However, if the epidemic lasts for a long time and the international situation does not improve significantly, the trend will be more prominent that China's economy takes domestic circulation as the mainstay. It is estimated that during the 14th Five-Year Plan period, the average annual economic growth rate will range from 5.6 to $6.0 \%$, and the elasticity of energy consumption will drop to 0.35 . Energy consumption will grow at an average annual rate of around $2 \%$, with an annual increase of about 100 million tons of standard coal. Total energy consumption can be controlled at 5.5 billion tons of standard coal, and energy consumption per unit of GDP is expected to fall by another $16 \%$. 


\subsection{Industrial energy consumption is slowing down}

The growth rate of traditional infrastructure construction will slow down or even gradually decrease, the proportion of energy-intensive industries will decline, and industrial energy consumption will reach its peak (about 3.3 billion tons of standard coal) and then enter a downward range. Traffic energy consumption will continue to grow during the 14th Five-Year Plan period, and the rapid development of new energy vehicles will drive a substantial increase in traffic electricity consumption. The peak of traffic energy consumption is expected to be reached during the 15th or even the 16th Five-Year Plan period.

\subsection{The level of social electrification will be enhanced}

During the 14th Five-Year Plan period, the modern service sector will continue to expand, the integration of digital economy and traditional industries will accelerate, and smart transportation and other new models and forms of business will rise rapidly, which will further drive the growth of power demand. Domestic electricity consumption for urban and rural residents will continue to grow steadily. The advantages of clean, safe and convenient electric energy will facilitate the substitution of electric energy. The electrification level of the whole society will go up a big step further.

\section{Suggestions for Energy Standardization System}

(I) Continue to improve business environment and market competition environment, promote renewable energy development through competition, and rely on the market to guide the selection of energy technology routes. Accelerate the establishment and improvement of electricity spot, futures and ancillary service markets to realize the pricing of renewable energy in different time and space.

(II) Give full play to local initiatives and create a competitive mechanism and atmosphere in which local governments compete to promote clean and low-carbon energy transformation in light of their local conditions; encourage local governments to learn from and compete with each other, and vigorously develop distributed energy systems and smart energy systems in cities.

(III) Consider to include and improve energy waste index in the performance evaluation of local energy conservation. Direct and indirect energy consumption driven by construction projects accounts for about $40 \%$ of China's total energy consumption. The short life of buildings, and demolition, major repair and reconstruction constitute the biggest waste of energy in China at present.

\section{Acknowledgments}

Project under National Key R\&D Program "Research on Technical Solutions and Energy Efficiency Standards of
Advanced and Efficient Medium and Small Asynchronous Motors" (2019YFE0192300)

\section{References}

1. Nancy L. Black, W. Patrick Neumann, Ian Noy. Proceedings of the 21st Congress of the International Ergonomics Association (IEA 2021) [M].:2021-0506.

2. Haroon Ur Rashid Khan, Muhammad Siddique, Khalid Zaman, Sheikh Usman Yousaf, Alaa Mohamd Shoukry, Showkat Gani, Sasmoko, Aqeel Khan, Sanil S. Hishan, Hummera Saleem. The impact of air transportation, railways transportation, and port container traffic on energy demand, customs duty, and economic growth: Evidence from a panel of low-, middle-, and high -income countries[J]. Journal of Air Transport Management,2018,70.

3. Lester C. Hunt, Yasushi Ninomiya, Primary energy demand in Japan: an empirical analysis of long-term trends and future $\mathrm{CO} 2$ emissions[J], Energy Policy 33. 2005

4. Shiwei Yu, Yi-Ming Wei, Ke Wang. China's primary energy demands in 2020: Predictions from an MPSORBF estimation model. Energy Conversion and Management 6.2012

5. Tong Guangrong, Yang Yanjun. A State-space Approach to Estimate Energy Demand Model in China. Energy Procedia 5.2011 